\title{
Níveis Nutricionais de Cálcio e Fósforo Disponível para Aves de Reposição Leves e Semipesadas de 0 a 6 Semanas de Idade ${ }^{1}$
}

\section{José Geraldo de Vargas Junior ${ }^{2}$, Luiz Fernando Teixeira Albino ${ }^{3}$, Horacio Santiago Rostagno ${ }^{3}$, Paulo Cézar Gomes ${ }^{3}$, Edwiney Sebastião Cupertino ${ }^{4}$, Débora Cristine Oliveira Carvalho 4 , Adriana Helena do Nascimento ${ }^{5}$}

\begin{abstract}
RESUMO - Foram realizados quatro experimentos utilizando 720 aves leves e 720 aves semipesadas de 0 a 6 semanas de idade, distribuídas em um delineamento inteiramente ao acaso, com cinco níveis de cálcio $(0,70 ; 0,80 ; 0,90 ; 1,00$ e $1,10 \%)$ ou com cinco níveis de fósforo disponível $(0,30 ; 0,35 ; 0,40 ; 0,45$ e $0,50 \%)$, com quatro repetições e 18 aves por unidade experimental. As rações experimentais foram formuladas à base de milho e de farelo de soja, contendo $2.900 \mathrm{kcal}$ de energia metabolizável/ kg de ração, $18 \%$ de proteína bruta, 0,70\% de cálcio para os experimentos de cálcio e $0,30 \%$ de fósforo disponível para os experimentos de fósforo. Ração e água foram fornecidas à vontade durante todo o período experimental. As características avaliadas foram ganho de peso, consumo de ração, conversão alimentar, resistência óssea, cinza óssea e cálcio ósseo (experimentos de cálcio) ou fósforo ósseo (experimentos de fósforo disponível). Por meio das características avaliadas foram estimadas exigências de 0,937 e $0,961 \%$ de cálcio e 0,420 e $0,423 \%$ de fósforo disponível, para aves leves e semipesadas, respectivamente.
\end{abstract}

Palavras-chave: aves de reposição leves, aves de reposição semipesadas, cálcio, fósforo disponível, exigência nutricional

\section{Nutritional Levels of Calcium and Available Phosphorus for White-Egg Pullets and Brown-Egg Pullets from 0 to 6 Weeks of Age}

\begin{abstract}
Four experiments were accomplished using 720 white-egg pullets and 720 brown-egg pullets from 0 to 6 age weeks, were allotted to a completely randomized design with five calcium levels $(.70, .80, .90,1.00$, and 1.10\%) or five levels of available phosphorus $(.30, .35, .40, .45$, and $.50 \%)$, with four replicates and 18 pullets for experimental unit. The experimental diets were formulated with soybean meal and corn to contain $2900 \mathrm{kcal}$ of metabolizable energy $/ \mathrm{kg}$ of diet, $18 \%$ crude protein, .70\% calcium for calcium experiments and $.30 \%$ of available phosphorus for phosphorus experiments. Diets and water were ad libitum fed during the experimental period. The evaluated characteristics were weight gain, feed intake, feed: gain ratio, bone resistance, bone ash and bone calcium (calcium experiments) or bone phosphorus (experiments of available phosphorus). Requirements of .937\% and .961\% of calcium and $.420 \%$ and $.423 \%$ of available phosphorus for white-egg pullets and brown-egg pullets, respectively, were estimated.
\end{abstract}

Key Words: white-egg pullets, brown-egg pullets, calcium, available phosphorus, nutritional requirements

\section{Introdução}

A produção avícola é dividida em aves para produção de carne e aves para produção de ovos. As aves produtoras de ovos, por sua vez, têm seu período de vida dividido nas fases de crescimento e produção de ovos. A fase de crescimento, subdivide-se em fases de cria e recria, que possuem características distintas e baseiam-se em alterações fisiológicas determinantes na formação da estrutura corporal. Assim, qualquer mudança no ritmo de crescimento destas aves, durante as fases de cria e recria, pode acarretar efeito sobre a produtividade na fase de produção de ovos.
O cálcio e o fósforo são os principais minerais utilizados no desenvolvimento das aves, associados principalmente ao metabolismo, particularmente na formação óssea, sendo que aproximadamente 98 a $99 \%$ do cálcio total do organismo e 80 a $85 \%$ do fósforo estão presentes nos ossos. Dessa forma, os ossos são grandes depósitos para suprir a necessidade circulante destes elementos químicos, sofrendo constante remodelagem e renovação. Se a concentração de cálcio no sangue começa a diminuir, rapidamente o cálcio é mobilizado dos ossos para elevar o nível sangüíneo ao normal.

\footnotetext{
${ }_{1}^{1}$ Parte da tese de Doutorado apresentado pelo primeiro autor à UFV

2 Zootecnista, DSc em Nutrição de Monogástricos. E.mail: jgvargas@bol.com.br

3 Professor do DZO/ UFV, Campus Universitário - Viçosa MG, Brasil, CEP: 36571-000.

${ }^{4}$ Estudante de Pós-Graduação em Zootecnia, DZO/ UFV, Viçosa MG, Brasil.

${ }^{5}$ Zootecnista, DSc em Nutrição de Monogástricos, Ajinomoto Biolatina, São Paulo, SP - Brasil
} 
Durante a absorção, o metabolismo e a excreção, o cálcio e fósforo interagem-se, o que faz com que haja uma relação em torno de 2: 1, havendo pouca variação nestes valores (Scott et al., 1982). Quando o cálcio está em excesso, pode haver interferência na disponibilidade de outros minerais, como fósforo, magnésio, manganês e zinco, causando deficiência secundária. Consumos altos de cálcio podem alterar a utilização de fósforo, devido à alteração da relação cálcio: fósforo (Anderson et al., 1995). Entretanto, altos níveis de fósforo também podem causar deficiência de cálcio.

Estudos com fósforo e cálcio têm sido baseados em ganho de peso, conversão alimentar e dados de cinza e resistência óssea, ou seja, são determinados por métodos empíricos, que estabelece nível dietético mínimo que maximize ou minimize características de desempenho. No geral são utilizadas recomendações de máxima resistência ou cinza óssea. De acordo com Rostagno et al. (1996), a exigência para otimizar desempenho das aves é inferior à exigência para maximizar a resistência óssea.

As aves, em geral, têm a capacidade de regular o consumo de cálcio de forma a atender seu requerimento (Classen \& Scott, 1982), logo em rações deficientes há tendência de aumento no consumo. Dessa forma, rações com altos níveis de cálcio, o consumo ficaria reduzido. Taher et al. (1984) observaram que aves alimentadas com alto nível de cálcio na dieta ou em níveis adequados, o consumo foi menor do que quando alimentados com baixos níveis de cálcio. Com a redução da ingestão de alimento, espera-se efeito negativo no peso corporal. No entanto, as aves podem ter redução no peso corporal, sem que haja efeito no tamanho no estrutural em termos absoluto (Leeson \& Summers, 1997).

Scott et al. (1976), citados por Carew \& Foss (1980), constataram que, com a redução de $0,41 \%$ de fósforo disponível para 0,35 ou $0,30 \%$, no período de 0 a 8 semanas, o ganho de peso e consumo de ração foram reduzidos, enquanto a conversão alimentar não foi afetada. O requerimento é maior em aves jovens, quando a taxa de crescimento fracionário é alta, e diminui em adultas, quando o peso corporal é alcançado.

O objetivo do presente experimento foi estimar os requerimentos nutricionais de cálcio e fósforo disponível para aves de reposição leves e semipesadas de 0 a 6 semanas de idade.

\section{Material e Métodos}

Os experimentos foram realizados no setor de avicultura e no Laboratório de Nutrição Animal do Departamento de Zootecnia da Universidade Federal de Viçosa, no período de janeiro a março de 1999. Foram utilizados 1.440 pintos de postura, sendo 720 aves leves (Hy Line W36) e 720 aves semipesadas (Hy Line Brown). O período experimental foi de $0 \mathrm{a}$ 6 semanas de idade.

As aves foram utilizadas em quatro experimentos, sendo dois para determinação das exigências de cálcio e dois para determinação das exigências de fósforo disponível, sendo que para cada nutriente estudado (cálcio ou fósforo disponível) foram determinadas as exigências nutricionais para aves leves e semipesadas.

As rações experimentais utilizadas foram à base de milho e de farelo de soja, de forma a atender as recomendações nutricionais segundo Rostagno et al. (1994) e NRC (1994), exceto para cálcio na determinação das exigências de cálcio e para fósforo disponível na determinação da exigências de fósforo. Foram utilizadas duas rações basais (Tabela 1), uma para determinação da exigência de cálcio e a outra para determinação da exigência de fósforo disponível. Estas duas rações continham $18 \%$ de proteína bruta e $2900 \mathrm{kcal}$ de EM/ kg de ração. Água e ração foram fornecidas à vontade.

Nos experimentos para determinação das exigências de cálcio, as aves foram submetidas a ração deficiente em cálcio e suplementada com calcário em substituição ao material inerte, para obter cinco níveis $(0,70 ; 0,80 ; 0,90 ; 1,00$ e 1,10\%) de cálcio na ração. Já nos experimentos para determinação das exigências de fósforo disponível, as aves foram submetidas a uma ração basal deficiente em fósforo disponível e suplementada com fosfato bicálcico e calcário, em substituição ao material inerte, para obter cinco níveis $(0,30 ; 0,35 ; 0,40 ; 0,45$ e $0,50 \%)$ de fósforo disponível nas rações. Assim, as rações para os experimentos de cálcio possuíam o mesmo nível de fósforo disponível e as rações para os experimentos de fósforo disponível, o mesmo nível de cálcio.

As características avaliadas foram ganho de peso (g/ ave/ dia), consumo de ração (g/ ave/ dia), conversão alimentar, resistência óssea à quebra $(\mathrm{kgf} / \mathrm{mm})$, cinza óssea (\%) e cálcio ósseo (\%) para os experimentos de cálcio e fósforo ósseos (\%) para os 
Tabela 1 - Composição percentual e valores nutricionais calculados das rações experimentais para experimentos de cálcio (Ração 1) e experimentos de fósforo disponível (Ração 2)

Table 1 - Percentage composition and calculated nutritional values of the experimental diets for experiments with calcium (Diet 1) and experiments with available phosphorus (Diets 2)

\begin{tabular}{|c|c|c|}
\hline $\begin{array}{l}\text { Ingredientes } \\
\text { Ingredients }\end{array}$ & $\begin{array}{l}\text { Ração } 1 \\
\text { Diet } 1\end{array}$ & $\begin{array}{c}\text { Ração } 2 \\
\text { Diet } 2\end{array}$ \\
\hline Milho (Corn) & 66,957 & 66,957 \\
\hline Farelo de soja (Soybean meal) & 26,572 & 26,572 \\
\hline Calcário (Limestone) & 0,588 & 1,445 \\
\hline Fosfato bicálcico (Dicalcium phosphate) & 1,578 & 1,037 \\
\hline DL-Metionina (DL-Methionine) & 0,122 & 0,122 \\
\hline Sal (Salt) & 0,291 & 0,291 \\
\hline Cloreto colina $60 \%$ (Choline cloret $60 \%$ ) & 0,050 & 0,050 \\
\hline Suplemento vitamínico ${ }^{1}$ (Vitamin supplement) & 0,100 & 0,100 \\
\hline Suplemento mineral ${ }^{2}$ (Mineral supplement) & 0,050 & 0,050 \\
\hline Virginamicina $^{3}$ (Virginamicin) & 0,050 & 0,050 \\
\hline Anticoccidiano 4 (Anticoccidiostatic) & 0,060 & 0,060 \\
\hline Antioxidante ${ }^{5}$ (Antioxidant) & 0,010 & 0,010 \\
\hline Inerte (Inert) & 3,573 & 3,256 \\
\hline \multicolumn{3}{|l|}{ Composição calculada (Calculated composition) } \\
\hline Energia metabolizável (kcal/kg) (Metabolizable energy) & 2900 & 2900 \\
\hline Proteína bruta $(\%)$ (Crude protein) & 18,00 & 18,00 \\
\hline Metionina (\%) (Methionine) & 0,407 & 0,407 \\
\hline Metionina + Cistina $(\%)($ Methionine + Cystine $)$ & 0,711 & 0,711 \\
\hline Lisina $(\%)($ Lysine $)$ & 0,923 & 0,923 \\
\hline Treonina (\%) (Threonine) & 0,654 & 0,654 \\
\hline Triptofano (\%) (Tryptophan) & 0,232 & 0,232 \\
\hline Cálcio (\%) (Calcium) & 0,700 & 0,900 \\
\hline Fósforo total (\%) (Total phosphorus) & 0,609 & 0,514 \\
\hline Fósforo disponível (\%) (Available phosphorus) & 0,400 & 0,300 \\
\hline Sódio $(\%)$ (Sodium) & 0,154 & 0,154 \\
\hline
\end{tabular}

${ }_{1}^{1}$ Rovimix (Roche)- Conteúdo (Content) vit. A - 10.000 .000 UI; vit. D3 - 2.000.000 Ul; vit. E - 30.000 Ul; vit. B1 - 2,0 g; vit. B6 - 4,0 g; Ac. pantotênico (Pantothenic acid) - 12,0 g; Biotina (Biotin)- 0,10 g; vit. K3 - 3,0 g; Ácido fólico (Folic acid)- $1,0 \mathrm{~g}$; Ácido nicotínico (Nicotinic acid) - 50,0 g; vit. B12 - 15.000 mcg; Selênio (Selenium) - 0, 25 g; e Veículo q. s. p. - 1.000 g.

${ }^{2}$ Roligomix (Roche) - Conteúdo (Content): Mn 16,0 g; Fe - 100,0 g; Zn-100,0 g; Cu-20,0 g; Co - 2,0 g ; l - 2,0 g; e Veículo q. s. p. - 1.000 g.

${ }^{3}$ Stafac ${ }^{\circledR} 20$.

${ }^{4}$ Coxistac ${ }^{\circledR}$ - Salinomicina (Salinomicin) - 12\%.

5 Hidroxi Butil Tolueno.

experimentos de fósforo disponível. Para obtenção dos parâmetros ósseos, foram abatidas três aves por unidade experimental, dentro do peso médio da unidade, onde foram retiradas as tíbias direita e esquerda, para posterior análises de resistência, cinza e mineral no osso.

As análises dos teores de cinzas, de cálcio e de fósforo no osso, foram realizadas de acordo com a metodologia descrita por Silva (1990a), e os parâmetros de resistência óssea foram através do osso in natura, em prensa INSTRON- modelo 4204, pertencentes ao Laboratório de Papel e Celulose do Departamento de Engenharia Florestal da Universidade Federal de Viçosa. Após as análises de resistência óssea, os ossos foram desengordurados em extrator tipo "Soxlet" e colocados em estufa a $55^{\circ} \mathrm{C}$ durante uma hora, sendo triturados logo após para análises de cálcio e fósforo.
Para todos os experimentos (cálcio e fósforo), as aves foram distribuídas em um delineamento inteiramente ao acaso, em cinco tratamentos, quatro repetições e 18 aves por unidade experimental, onde foram distribuídas com um dia de idade e peso médio de 37,5 e $37,3 \mathrm{~g}$, para aves leves e semipesadas, respectivamente.

As análises estatísticas dos resultados obtidos foram realizadas de forma conjunta (aves leves e semipesadas), dentro do nutriente estudado (cálcio ou fósforo disponível), usando o programa SAEG Sistema para Análises Estatísticas e Genéticas (UFV, 1997). Foi feita análise de variância, com posterior uso de regressão polinomial, para cada variável estudada, além do teste de F na comparação de médias dos tratamentos entre aves leves e semipesadas. O modelo estatístico utilizado foi: 


$$
Y_{i j k}=\mu+N_{i}+P_{j}+N_{i} / P_{j}+E_{i j k}
$$

em que: $Y_{i j k}=$ parâmetro observado na unidade experimental $\mathrm{k}$, do nível de cálcio ou fósforo disponível $\mathrm{i}$, dentro do tipo de ave $\mathrm{j}, \mathrm{j}=$ ave leve ou semipesada; $\mu=$ média geral observada; $\mathrm{N}_{\mathrm{i}}=$ efeito do nível de nutriente i (cálcio ou fósforo disponível), i = 1, 2, 3, 4 e 5; $\mathrm{Pj}=$ efeito do tipo de ave de reposição $\mathrm{j}$ ( ave leve ou semipesada); $\mathrm{N}_{\mathrm{i}} / \mathrm{P}_{\mathrm{j}}=$ efeito do nível de nutriente $\mathrm{i}$, dentro do tipo de ave $\mathrm{j} ; \mathrm{E}_{\mathrm{ijk}}=$ erro aleatório associado a cada observação.

\section{Resultados e Discussão}

\section{Exigência nutricional de cálcio}

Observa-se, na Tabela 2, que os diferentes níveis de cálcio não afetaram o consumo de ração, a conversão alimentar e o teor de cinza óssea de aves leves e semipesadas e o teor de cálcio ósseo das aves leves. Entretanto, verifica-se que, apesar de não ter havido diferenças nas características citadas, as aves leves apresentaram, em termos numéricos, maior consumo de ração do que as aves semipesadas; esta diferença no consumo foi suficiente para fazer com que, na média, as aves leves apresentassem pior conversão alimentar.

Segundo Hamilton \& Cipera (1981), as aves têm capacidade de se adaptar a dietas contendo baixo nível de cálcio aumentando a capacidade de absorção intestinal. Além disso, as aves jovens têm melhor capacidade de absorver cálcio do que aves velhas (Leeson et al., 1986). Entretanto, segundo Silva (1990b), as aves, em geral, têm a capacidade de regular o consumo de cálcio de forma a atender as necessidades nutricionais. Dessa forma, uma vez que não houve diferenças de consumo entre os diversos níveis de cálcio estudados, parte-se do princípio de que houve aumento da absorção intestinal. Porém, esta maior absorção não foi suficiente para que houvesse aumento da cinza e do cálcio ósseo. Estes resultados discordam dos obtidos por Frost \& Roland (1989), que observaram maiores teores de cinza óssea em ossos de aves alimentadas com rações contendo maiores níveis de cálcio.

Ao observar o ganho de peso (g/ave/dia), verificou-se que os níveis de cálcio provocaram efeito quadrático para ambos os tipos de aves. Para aves leves foi observado máximo ganho de peso de 7,69 g/ ave/dia no nível de $0,937 \%$ de cálcio (Tabelas 2 e 3), enquanto para aves semipesadas este ganho foi de $9,34 \mathrm{~g}$ /ave/dia para $0,895 \%$ de cálcio na ração. Apesar deste efeito quadrático, os resultados não foram suficientes para afetar a conversão alimentar. Segundo Leeson \& Summers (1997), com redução de

Tabela 2 - Efeitos dos níveis nutricionais de cálcio sobre o desempenho e parâmetros ósseos de aves de reposição leves (L) e semipesadas (SP)

Table 2 - Effects of nutritional levels of calcium on performance and bone parameters of white-egg pullets ( $L)$ and brown-egg pullets $(S P)$

\begin{tabular}{|c|c|c|c|c|c|c|c|c|c|c|c|c|}
\hline $\begin{array}{l}\text { Cálcio } \\
(\%) \\
\text { Calcium }\end{array}$ & $\begin{array}{r}\text { Consu } \\
\text { ração (g } \\
\text { Feed } \\
\text { (g/chich }\end{array}$ & $\begin{array}{l}\text { de } \\
\text { e/dia) } \\
\text { ake } \\
\text { day) }\end{array}$ & $\begin{array}{c}\mathrm{Ga} \\
\mathrm{de} \\
(\mathrm{g} / \mathrm{av} \\
\text { Weig } \\
\text { (g/chich }\end{array}$ & $\begin{array}{l}\text { dia) } \\
\text { ain } \\
\text { (day) }\end{array}$ & $\begin{array}{r}\text { Cony } \\
\text { alim } \\
\text { Feed: } g\end{array}$ & $\begin{array}{l}\text { são } \\
\text { tar } \\
\text { ratio }\end{array}$ & $\begin{array}{r}\text { Resi } \\
\text { óssea (1 } \\
\text { Boner }\end{array}$ & $\begin{array}{l}\text { ficia } \\
\mathrm{f} / \mathrm{mm} \text { ) } \\
\text { istant }\end{array}$ & $\begin{array}{r}\mathrm{C} \\
\text { ósse } \\
\text { Bor }\end{array}$ & $\begin{array}{l}\mathrm{za} \\
(\%) \\
\text { ash }\end{array}$ & $\begin{array}{r}\text { Cá } \\
\text { ósse } \\
\text { Bone }\end{array}$ & $\begin{array}{l}\mathrm{o} \\
\%) \\
\text { cium }\end{array}$ \\
\hline & $\mathrm{L}$ & SP & $\mathrm{L}$ & SP & $\mathrm{L}$ & $\mathrm{SP}$ & $\mathrm{L}$ & $\mathrm{SP}$ & $\mathrm{L}$ & $\mathrm{SP}$ & $\mathrm{L}$ & SP \\
\hline 0,70 & 29,47 & 29,93 & 7,20 & 8,93 & 4,10 & 3,35 & 5,11 & 5,65 & 38,83 & 39,22 & 24,11 & 24,38 \\
\hline 0,80 & 29,08 & 28,15 & 7,42 & 9,24 & 3,93 & 3,05 & 5,07 & 6,19 & 38,70 & 38,09 & 24,08 & 22,93 \\
\hline 0,90 & 29,12 & 28,39 & 7,72 & 9,28 & 3,77 & 3,06 & 5,36 & 6,73 & 39,51 & 40,36 & 24,37 & 26,06 \\
\hline 1,00 & 29,91 & 28,55 & 7,73 & 9,29 & 3,87 & 3,07 & 5,40 & 6,38 & 40,16 & 39,85 & 25,36 & 25,17 \\
\hline 1,10 & 27,60 & 28,59 & 7,41 & 8,84 & 3,73 & 3,24 & 5,73 & 6,40 & 39,98 & 39,83 & 24,82 & 25,67 \\
\hline Média ${ }^{1}$ & 29,04 & 28,72 & $7,49 b$ & $9,12 \mathrm{a}$ & $3,88 \mathrm{~b}$ & $3,16 \mathrm{a}$ & $5,34 b$ & $6,27 \mathrm{a}$ & 39,44 & 39,47 & 24,55 & 24,84 \\
\hline $\begin{array}{l}\text { Average } \\
\text { Efeito } \\
\text { Effects }\end{array}$ & NS & NS & $\mathrm{Q}^{*}$ & $\mathrm{Q}^{*}$ & NS & NS & $\mathrm{L}^{*}$ & $\mathrm{Q}^{*}$ & NS & NS & NS & $\mathrm{L}^{*}$ \\
\hline $\mathrm{CV}(\%)$ & 7,7 & & & & & & & & & & & \\
\hline
\end{tabular}

${ }^{1}$ Médias seguidas por uma mesma letra dentro de um mesmo parâmetro não diferem entre si pelo teste $F$; CV = coeficiente de variação. $\mathrm{Q}$ - efeito quadrático; $\mathrm{L}$ - efeito linear; NS efeito não-significativo; ${ }^{*}(\mathrm{P}<0,05) ;{ }^{* *}(\mathrm{P}<0,01)$. Resistência óssea em kgf/ mm, em que $1 \mathrm{~N}$ $=0,1020 \mathrm{kgf} / \mathrm{mm}$.

Mean followed by the same letter in the same parameter do not differ by $F$ test; $C V=$ coefficient of variation; $Q=q u a d r a t i c$ effect; $L=$ linear effect; $\mathrm{NS}=$ not significant effect; ${ }^{*}(P<.05) ;{ }^{* *}(P<.01)$. Bone resistance in $\mathrm{kgf} / \mathrm{mm}$, in which $1 \mathrm{~N}=.1020 \mathrm{kgf} / \mathrm{mm}$. 
consumo, há diminuição no peso corporal e, conseqüentemente, no ganho de peso. Entretanto, foi observado que, além de não ter havido alteração no consumo de ração, o cálcio disponível para os processos metabólicos normais influenciou o ganho de peso, uma vez que a quantidade de cálcio ingerido aumentou, à medida que se elevaram os níveis de cálcio na ração. Esta resposta do ganho de peso, provavelmente, está relacionada com as observações feitas por Hamilton \& Cipera (1981), quanto ao aumento da absorção intestinal de cálcio, quando as aves são alimentadas com rações deficientes em cálcio.

Em estudos de cálcio e de fósforo, a resistência óssea é um dos principais parâmetros a serem analisados, porque o osso é o principal reservatório destes minerais no corpo do animal. Assim, em situações de deficiência prolongada de cálcio, ocorre mobilização óssea de forma a suprir as necessidades do organismo (Zoollitsch et al., 1996; Wilson \& Duff, 1991, citados por Rennie et al., 1997).

A resistência óssea de aves leves elevou-se, à medida que houve aumento do cálcio na ração, enquanto aves semipesadas apresentaram efeito quadrático, com máxima resistência óssea $(6,59 \mathrm{kgf} / \mathrm{mm})$ ao nível de $0,961 \%$ de cálcio na ração (Tabela 3). Em geral, a quantidade de cálcio necessária na ração para maximizar a resistência óssea é maior que a quantidade necessária para maximizar qualquer outro parâmetro produtivo (Rostagno et al., 1996). Estudando a exigência de cálcio, Narváez et al. (1997) encontraram que dentre os parâmetros avaliados a resistência óssea foi a característica que teve a maior exigência de cálcio.

Outro parâmetro a ser observado diz respeito à relação entre cálcio e fósforo, que, segundo Scott et al. (1982), está em torno de 2:1. Qualquer alteração nesta relação provoca mudança na utilização do nutriente pelo organismo animal. Assim, em ração com menores níveis de cálcio, a relação é menor, o que pode ter feito com que o aumento do cálcio na ração proporcionasse aumento linear do cálcio no osso para aves semipesadas, devido à maior quantidade de cálcio disponível para a deposição óssea (Tabela 3). Entretanto, este aumento do cálcio no osso, com o incremento de cálcio da ração observado somente para aves semipesadas, pode estar relacionado ao fato de o ritmo de crescimento deste tipo de ave ser maior que o de aves leves.

Geralmente, as recomendações nutricionais baseiam-se nas características produtivas dos animais, desta forma, foi observado que aves leves requerem $0,937 \%$ e aves semipesadas, $0,961 \%$ de cálcio, resultados estes semelhantes aos recomendados por Rostagno et al. (1994). No entanto, estes autores fazem a recomendação para um único tipo de ave, mas sugerem ajustar os níveis em função do consumo das aves.

\section{Exigência nutricional de fósforo disponível}

Pelos resultados de desempenho e de parâmetros ósseos de aves submetidas a diferentes níveis de fósforo disponível (Tabela 4), pode-se observar que, entre as variáveis estudadas, o consumo de ração, a resistência e a cinza óssea não foram influenciados pelos tratamentos.

Ao observar o ganho de peso, nota-se que, independentemente do tipo de ave, os níveis altos e baixos de fósforo disponível na ração foram prejudiciais para o desempenho das aves, o que fez com que

Tabela 3 - Exigência de cálcio para aves de reposição leve (L) e semipesada (SP), considerando desempenho e parâmetros ósseos

Table 3 - Requirements of calcium for white-egg pullets $(L)$ and brown-egg pullets (SP), considering performance and bone parameters

\begin{tabular}{|c|c|c|c|c|c|c|}
\hline \multirow[t]{2}{*}{$\begin{array}{l}\text { Parâmetro } \\
\text { Parameter }\end{array}$} & & \multirow[t]{2}{*}{$\begin{array}{l}\text { Equação } \\
\text { Equation }\end{array}$} & \multirow[t]{2}{*}{$\mathrm{R}^{2}$} & \multirow[t]{2}{*}{$\begin{array}{c}\operatorname{Max} / \\
\min \end{array}$} & \multicolumn{2}{|c|}{$\begin{array}{l}\text { Exigências } \\
\text { Requirements }\end{array}$} \\
\hline & & & & & $(\%)$ & $\begin{array}{c}(\% / \text { Mcal EM) } \\
(\% / \text { Mcal ME) }\end{array}$ \\
\hline GP & $\mathrm{L}$ & $Y=-0,9415+18,4524 x-9,8449 x^{2}$ & 0,91 & 7,69 & 0,937 & 0,323 \\
\hline$W G$ & SP & $Y=0,4079+19,9700 x-11,1609 x^{2}$ & 0,95 & 9,34 & 0,895 & 0,309 \\
\hline $\mathrm{RO}$ & $\mathrm{L}$ & $\mathrm{Y}=3,9111+1,5839 \mathrm{x}$ & 0,81 & - & $\geq 1,10$ & - \\
\hline$B O$ & $\mathrm{SP}$ & $Y=-6,0725+26,3550 x-13,7077 x^{2}$ & 0,87 & 6,59 & 0,961 & 0,331 \\
\hline Ca ósseo & SP & $\mathrm{Y}=20,5290+4,8209 \mathrm{x}$ & 0,38 & - & $\geq 1,10$ & - \\
\hline
\end{tabular}

GP - ganho de peso (g/ ave/ dia); RO - resistência óssea (kgf/ mm); Ca ósseo - cálcio no osso

$W G$ - weight gain (g/ chicken/ day); BO - bone resistant (kgf/ mm); Ca bone - calcium in bone. 
a resposta apresentasse forma quadrática $(\mathrm{P}<0,05)$. As aves leves tiveram o ganho de peso maximizado (7,83 g/ ave/ dia) em nível de 0,420\% de fósforo disponível, e as aves semipesadas apresentaram o maior ganho de peso $(8,77 \mathrm{~g} / \mathrm{ave} / \mathrm{dia})$ no nível de $0,423 \%$ (Tabela 5).

Uma vez que não houve diferença no consumo de ração, o ganho de peso de aves leves foi o principal parâmetro a afetar de forma linear decrescente a conversão alimentar (Tabela 4). A conversão alimentar de aves semipesadas não foi afetada de forma significativa $(\mathrm{P}<0,05)$. Estes resultados discordam dos obtidos por Scott et al. (1976), citados por Carew \& Foss (1980), os quais observaram que, com a redução de $0,41 \%$ de $P$ disponível para 0,35 ou $0,30 \%$, no período de 0 a 8 semanas, o ganho de peso e o consumo de ração foram reduzidos, enquanto a conversão alimentar não foi afetada.

Apesar de o consumo de ração não ter sido diferente entre os tratamentos, o consumo de fósforo elevou-se, à medida que o nível deste aumentou na ração. Assim, a ave tinha condições nutricionais para manter padrão de resistência óssea, ao mesmo tempo que tinha fósforo suficiente para o crescimento corporal, uma vez que não houve efeito significativo sobre os parâmetros ósseos. Os resultados encontrados contra- dizem os obtidos por Bailey et al. (1986), sendo que, quando o osso não é bem formado, além de problemas de perna, ocorre redução do ganho de peso.

Comparando-se aves leves e semipesadas, verificou-se que os resultados de consumo de ração e cinza óssea não apresentaram diferenças $(\mathrm{P}>0,05)$. Porém, ganho de peso, conversão alimentar, resistência óssea e fósforo no osso, de aves semipesadas, apresentaram em média melhores resultados do que aves leves, pelo teste de F, mostrando melhor utilização do fósforo para a formação óssea.

Cálcio e fósforo interagem-se, de forma que o excesso ou diminuição de um deles pode afetar a utilização do outro pelo corpo animal. Assim, a relação cálcio e fósforo é em torno de 2: 1 e varia pouco (Scott et al., 1982). Uma vez que as rações utilizadas nos tratamentos mantiveram a mesma quantidade de cálcio, variando somente os níveis de fósforo disponível, houve alteração da relação cálcio: fósforo, fazendo com que, à medida que houvesse aumento do fósforo na ração, a relação entre os minerais fosse reduzida e houvesse maior aproveitamento do fósforo para deposição óssea. Isto, provavelmente, foi a causa do efeito linear crescente para fósforo no osso para aves semipesadas (Tabela 5). Entretanto, tal situação

Tabela 4 - Efeitos dos níveis nutricionais de fósforo disponível sobre desempenho e parâmetros ósseos de aves de reposição leves (L) e semipesadas $(\mathrm{SP})$ de 0 a 6 semanas de idade

Table 4 - Effects of nutritional levels of available phosphorus on performance and bone parameters of white-egg pullets (L) and brown-egg pullets $(S P)$

\begin{tabular}{|c|c|c|c|c|c|c|c|c|c|c|c|c|}
\hline \multirow[t]{2}{*}{$\begin{array}{l}\text { Fósforo } \\
\text { disponível } \\
\text { Available } \\
\text { phosphorus }\end{array}$} & \multicolumn{2}{|c|}{$\begin{array}{c}\text { Consumo de } \\
\text { ração (g/ave/dia) } \\
\text { Feed intake } \\
\text { (g/chicken/day) }\end{array}$} & \multicolumn{2}{|c|}{$\begin{array}{c}\text { Ganho } \\
\text { de peso } \\
\text { (g/ ave/ dia) } \\
\text { Weight gain } \\
\text { (g/chicken/day) }\end{array}$} & \multicolumn{2}{|c|}{$\begin{array}{c}\text { Conversão } \\
\text { alimentar } \\
\text { Feed: gain ratio }\end{array}$} & \multicolumn{2}{|c|}{$\begin{array}{c}\text { Resistência } \\
\text { óssea }(\mathrm{kgf} / \mathrm{mm}) \\
\text { Bone resistant } \\
(\mathrm{kgf} / \mathrm{mm})\end{array}$} & \multicolumn{2}{|c|}{$\begin{array}{c}\text { Cinza } \\
\text { óssea }(\%) \\
\text { Bone ash } \\
(\%)\end{array}$} & \multicolumn{2}{|c|}{$\begin{array}{c}\text { Fósforo } \\
\text { ósseo (\%) } \\
\text { Bone } \\
\text { phosphorus (\%) }\end{array}$} \\
\hline & $\mathrm{L}$ & SP & $\mathrm{L}$ & SP & $\mathrm{L}$ & SP & $\mathrm{L}$ & SP & $\mathrm{L}$ & SP & $\mathrm{L}$ & SP \\
\hline 0,30 & 28,85 & 28,78 & 7,33 & 8,33 & 3,94 & 3,46 & 5,30 & 6,32 & 41,92 & 40,24 & 5,62 & 7,42 \\
\hline 0,35 & 29,31 & 28,23 & 7,55 & 8,55 & 3,88 & 3,31 & 5,36 & 5,94 & 39,18 & 43,24 & 5,50 & 7,01 \\
\hline 0,40 & 29,87 & 29,38 & 7,80 & 8,85 & 3,82 & 3,32 & 5,48 & 6,49 & 40,20 & 38,49 & 5,88 & 7,45 \\
\hline 0,45 & 28,49 & 27,41 & 7,91 & 8,70 & 3,61 & 3,15 & 5,43 & 6,49 & 39,98 & 41,35 & 5,26 & 7,95 \\
\hline 0,50 & 27,47 & 30,00 & 7,53 & 8,61 & 3,66 & 3,48 & 5,08 & 6,43 & 39,20 & 41,80 & 5,35 & 7,93 \\
\hline Média $^{1}$ & 28,80 & 28,76 & $7,62 \mathrm{~b}$ & $8,61 \mathrm{a}$ & $3,78 \mathrm{~b}$ & $3,34 \mathrm{a}$ & $5,33 b$ & $6,33 a$ & 40,10 & 41,02 & $5,52 b$ & $7,55 \mathrm{a}$ \\
\hline $\begin{array}{l}\text { Average } \\
\text { Efeito }\end{array}$ & NS & NS & $\mathrm{Q}^{*}$ & $\mathrm{Q}^{1}$ & $\mathrm{L \#}^{2}$ & NS & NS & NS & NS & NS & NS & $\mathrm{L}^{*}$ \\
\hline $\begin{array}{l}\text { Effect } \\
\text { CV }(\%)\end{array}$ & \multicolumn{2}{|c|}{7,884} & \multicolumn{2}{|c|}{3,561} & \multicolumn{2}{|c|}{8,216} & \multicolumn{2}{|c|}{7,512} & \multicolumn{2}{|c|}{5,698} & \multicolumn{2}{|c|}{5,942} \\
\hline
\end{tabular}

${ }^{1}$ Médias seguidas por uma mesma letra dentro de um mesmo parâmetro não diferem entre si pelo teste $\mathrm{F}$.

$C V=$ coeficiente de variação. $Q=$ efeito quadrático; $L=$ efeito linear; $N S$ = efeito não-significativo; * $(P<0,05) ;{ }^{* *}(P<0,01)$. Resistência óssea em kgf/ mm, em que $1 \mathrm{~N}=0,1020 \mathrm{kgf} / \mathrm{mm}$.

${ }^{1}$ Mean followed by the same letter in same parameter do not differ by the test $F$.

$C V=$ coefficient of variation. $Q=$ quadratic effect; $L=$ linear effect; $N S=$ not significant effect; ${ }^{*}(P<.05) ;{ }^{* *}(P<.01)$. Bone resistance in $\mathrm{kgf} / \mathrm{mm}$, in which $1 \mathrm{~N}=.1020 \mathrm{kgf} / \mathrm{mm}$.

R. Bras. Zootec., v.32, n.6, p.1919-1926, 2003 (Supl. 2) 
Tabela 5 - Exigência de fósforo disponível para aves de reposição leve (L) e semipesada (SP), considerando desempenho e parâmetros ósseos

Table 5 - Requirements of available phosphorus for white-egg pullets (L) and brown-egg pullets (SP), considering performance and bone parameters

\begin{tabular}{|c|c|c|c|c|c|c|}
\hline \multirow[t]{2}{*}{$\begin{array}{l}\text { Parâmetro } \\
\text { Parameter }\end{array}$} & & \multirow[t]{2}{*}{$\begin{array}{l}\text { Equação } \\
\text { Equation }\end{array}$} & \multirow[t]{2}{*}{$\mathrm{R}^{2}$} & \multirow[t]{2}{*}{$\begin{array}{c}\operatorname{Max} / \\
\min \end{array}$} & \multicolumn{2}{|c|}{$\begin{array}{c}\text { Exigências } \\
\text { Requirements }\end{array}$} \\
\hline & & & & & $(\%)$ & $\begin{array}{c}\text { (\%/Mcal EM) } \\
(\% / \text { Mcal ME) }\end{array}$ \\
\hline GP & $\mathrm{L}$ & $Y=1,0319+32,4015 x-38,5898 x^{2}$ & 0,88 & 7,83 & 0,420 & 0,145 \\
\hline$W G$ & SP & $Y=3,3520+25,6315 x-30,2852 x^{2}$ & 0,89 & 8,77 & 0,423 & 0,146 \\
\hline CA & $\mathrm{L}$ & $Y=4,4511-1,6736 x$ & 0,85 & - & $\geq 0,50$ & - \\
\hline$F G$ & & & & & & \\
\hline $\begin{array}{l}\mathrm{P} \text { ósseo } \\
\text { P bone }\end{array}$ & SP & $Y=5,9801+3,9275 x$ & 0,62 & - & $\geq 0,50$ & - \\
\hline
\end{tabular}

GP - ganho de peso (g/ ave/ dia); RO - resistência óssea (kgf/ mm); Ca ósseo - cálcio no osso.

$W G$ - weight gain ( $\mathrm{g} /$ chickens/ day); BO - bone resistant ( $\mathrm{kgf/mm}$ ); Ca bone - calcium in bone.

não foi observada para aves leves, provavelmente pelo fato de que a proporção entre cálcio e fósforo não tem efeito tão pronunciado para aves leves devido ao ritmo de crescimento ser menor.

Segundo recomendações de Rostagno et al. (1994), a exigência nutricional de fósforo disponível para poedeiras em crescimento, na fase de 7 a 12 semanas de idade, é de $0,435 \%$, valores muito próximo ao obtidos no presente trabalho $(0,420 \%$ para aves leves e $0,423 \%$ para aves semipesadas). No entanto, os autores acima supracitados fazem a recomendação para aves leves e, pela diferença de consumo entre os tipos de aves, tem-se a recomendação para aves semipesadas.

\section{Conclusões}

As exigências estimadas de cálcio são de $0,937 \%$ (0,323\%/ Mcal de EM) ou $277 \mathrm{mg}$ de cálcio/ ave/ dia para aves leves e de $0,961 \%(0,331 \% /$ Mcal de EM) ou $274 \mathrm{mg}$ de cálcio/ ave/ dia para aves semipesadas, e as exigências nutricionais estimadas de fósforo disponível são de $0,420 \%(0,145 \% /$ Mcal de EM) ou $122 \mathrm{mg} /$ ave/ dia para aves leves e de 0,423\% $(0,146 \% /$ Mcal de EM) $120 \mathrm{mg} / \mathrm{ave} /$ dia para aves semipesadas.

\section{Literatura Citada}

ANDERSON, K.E.; HARVENSTEIN, G.B.; BRAKE, J. Effects of strain and rearing dietary regimens on brown-egg pullet growth and strain, rearing dietary regimens, density, and feed space effects on subsequent laying performance. Poultry Science, v.74, p.1079-1092, 1995.
BAILEY, C.A.; LINTON, S.; BRISTER, R. et al. Effects of gradel levels of dietary phosphorus on bone mineralization in the very young poultry. Poultry Science, v.65, p.1018-1020, 1986.

CAREW, L.B.; FOSS, D.C. Dietary phosphorus levels during growth of brown egg type replacement pullets. Poultry Science, v.59, p.812-818, 1980.

CLASSEN, H.L.; SCOTT, T.A. Self selection of calcium during the rearing and early laying periods of White Leghorn pullets. Poultry Science, v.61, p.2065-2074, 1982.

FROST, T.J.; SR ROLAND, D.A. The influence of various calcium and phosphorus levels on bone formation and production of pullets during peak production. Poultry Science, v.68, Supplement 1, Abstracts, 1989.

HAMILTON, R.M.G.; CIPERA, J.D. Effects dietary calcium levels during the brooding, rearing, and early laying period on feed intake, egg production, and shell quality of White Leghorn hens. Poultry Science, v.60, p.349-357, 1981.

LEESON, S.; JULIAN, R.J.; SUMMERS, J.D. Influence of prelay and early-lay dietary calcium concentration on performance and bone integrity of leghorn pullets. Canadian Journal Animal Science, v.66, p.1087-1095, 1986.

LEESON, S.; SUMMERS, J.D. Commercial poultry nutrition. 2.ed. Guelph-Ontário: Univerty Books, 1997. 355p.

NARVÁEZ, W.V.; ROSTAGNO, H.S.; SOARES, P.R. et al. Níveis de cálcio para poedeiras comerciais leves de 46 a 62 semanas de idade. In: REUNIÃO ANUAL DA SOCIEDADE BRASILEIRA DE ZOOTECNIA, 34., 1997, Juiz de Fora. Anais... Juiz de Fora: Sociedade Brasileira de Zootecnia, 1997. p. 27.

NATIONAL RESEARCH COUNCIL - NRC. Nutrient requirements of poultry. 9. rev. ed. Washington, DC.: 1994. $155 \mathrm{p}$.

RENNIE, J.S.; FLEMING, R.H.; McCORMACK, H.A. et al. Studies on effects of nutritional factors on bone structure and osteoporosis in laying hens. British Poultry Science, v.38, p.417-424, 1997.

ROSTAGNO, H.S.; BARBARINO JR., P.; BARBOZA, W.A. Exigências nutricionais de aves determinadas no Brasil. In: SIMPÓSIO INTERNACIONAL SOBRE EXIGÊNCIAS NUTRICIONAIS DE AVES E SUÍNOS, 1996, Viçosa, MG, Anais ... Viçosa, MG: Universidade Federal de VIçosa, 1996. p.361-388. 
ROSTAGNO, H.S.; SILVA, D.J.; COSTA, P.M.A. et al. Composição de alimentos e exigências nutricionais de aves e suínos (Tabelas brasileiras). Viçosa, MG: Universidade Federal de Viçosa, 1994. 61p.

SCOTT, M.L.; NESHEIM, M.C.; YOUNG, R.J. Essential inorganic elements: nutrition of the chicken. 3.ed. New York: M.L Scott Associates, 1982. p.287-304.

SILVA, D.J. Análises de alimentos (métodos químicos e biológicos). Viçosa, MG: Universidade Federal de Viçosa, 1990a. 165p.

SILVA, M.L.F. Exigências nutricionais de cálcio para galinhas reprodutoras de corte. Viçosa, MG: Universidade Federal de Viçosa, 1990. 58p. Dissertação (Mestrado em Zootecnia) Universidade Federal de Viçosa, 1990b.

TAHER, A.I.; GLEAVES, E.W.; BECK, M. Special calcium appetite in laying hens. Poultry Science, v.63, p.2261-2267, 1984.
UNIVERSIDADE FEDERAL DE VIÇOSA - UFV. SAEG Sistema de Análises Estatísticas e Genéticas. Versão 7.1. Viçosa, MG: 1997. 59p. (Manual do Usuário).

ZOOLLITSCH, W.; ZHIQIANG, C.; PEGURI, A. et al. Nutrient requirements of laying hens. In: SIMPÓSIO INTERNACIONAL SOBRE EXIGÊNCIAS NUTRICIONAIS DE AVES E SUÍNOS, 1996, Viçosa, MG. Anais ... Viçosa, MG: Universidade Federal de Viçosa, 1996. p.109-159.

Recebido em: 21/08/02

Aceito em: 18/03/03 